\title{
Achados patológicos e imuno-histoquímicos em bovinos com doença granulomatosa sistêmica pelo consumo de Vicia villosa (Leg. Papilionoideae) no Rio Grande do Sul ${ }^{1}$
}

\author{
Luciana Sonne'2, Djeison L. Raymundo², Fabiana M. Boabaid², Tatiane T.N. \\ Watanabe $^{2}$, Luiz G.S. Oliveira ${ }^{2}$, Itabajara S. Vaz Jr³ e David Driemeier ${ }^{2}$
}

\begin{abstract}
Sonne L., Raymundo D.L., Boabaid F.M., Watanabe T.T.N., Oliveira L.G.S., Vaz Jr I.S. \& Driemeier D. 2011. [Pathological and immunohistochemical findings in cattle affected by systemic granulomatous disease by consumption Vicia villosa (Leg. Papilionoideae) in Rio Grande do Sul.] Achados patológicos e imuno-histoquímicos em bovinos com doença granulomatosa sistêmica pelo consumo de Vicia villosa (Leg. Papilionoideae) no Rio Grande do Sul. Pesquisa Veterinária Brasileira 31(4):307-312. Setor de Patologia Veterinária, Faculdade de Veterinária, Universidade Federal do Rio Grande do Sul, Avenida Bento Gonçalves 9090, Porto Alegre, RS 91540-000, Brazil. E-mail: davetpat@ufrgs.br

The systemic granulomatous disease associated with consumption of Vicia villosa (Leg. Papilionoideae family) has been diagnosed in 5 cattle from 2005 to 2008. Affected cattle showed alopecia, crusted lesions on the skin, had itching, fever, decreased milk yield, anorexia and wasting. Average clinical course was 2 weeks. Three cattle died and two were euthanized in extremis. The main gross changes are alopecic and crusts in the skin, mainly on the face and neck. There also were multifocal to coalescent whitish nodules that infiltrated several organs, but especially lymph nodes, kidneys and hearth. Microscopic changes consisted of infiltration with lymphocytes, macrophages, epithelioid cells, giant multinucleated cells, eosinophils, and plasmocytes. Lymph nodes, kidneys, adrenal gland, spleen and liver from affected cattle showed varying degrees of granulomatous infiltration. Immunohistochemical procedures on samples from affected organs revealed that Tlymphocytes and macrophages/epithelioid cells/giant multinucleated cells were the main components of the inflammatory infiltrates, B-lymphocytes were only rarely seen within. The reduced numbers of cells marked by Ki-67 in the granulomatous lesions would indicate that cell proliferation was not responsible for the hypercellularity in the lesions and that rather the recruitment of macrophages and lymphocytes to the site inflammation probably accounted for the building up of the local cellular inflammatory infiltrate.
\end{abstract}

INDEX TERMS: Poisonous plants, Vicia villosa, Leguminosae Papilionoideae, plant poisoning, systemic granulo-matous disease, cattle, immunohistochemistry.

RESUMO.- A doença granulomatosa sistêmica associada ao consumo de Vicia villosa (Leg. Papilionoideae) foi diagnosticada em 5 bovinos no período de 2005 a 2008. Os bovinos apresentavam alopecia, lesões crostosas na pele,

\footnotetext{
${ }^{1}$ Recebido em 19 de julho de 2010.

Aceito em 17 de novembro de 2010.

2 Setor de Patologia Veterinária, Faculdade de Veterinária, Universidade Federal do Rio Grande do Sul (UFRGS), Av. Bento Gonçalves 9090, Porto Alegre, RS 91540-000, Brasil. *Autor para correspondência: davetpat@ufrgs.br

${ }^{3}$ Faculdade de Veterinária, UFRGS, Av. Bento Gonçalves, 9500, Prédio 43421, Porto Alegre, RS 91501-970.
}

prurido, febre, queda da produção leiteira, anorexia e emagrecimento. O curso clínico médio da doença foi de 2 semanas. Dos bovinos analisados três morreram e dois foram eutanasiados. As lesões macroscópicas de alopecia e crostas na pele eram localizadas principalmente na face e pescoço. Observava-se nódulos multifocais a coalescentes branco-acinzentados que infiltravam vários órgãos especialmente em linfonodos, rins e coração. As lesões microscópicas consistiam na infiltração de linfócitos, macrófagos, células epitelioides, células gigantes multinucleadas, eosinófilos e plasmócitos. Linfonodos, rins, adrenal, baço e fígado de todos os bovinos apresentaram infiltrado granulo- 
matoso, porém de intensidade variável. Nos testes imunohistoquímicos dos órgãos com infiltrado inflamatório, as principais células visualizadas foram os linfócitos $T$, seguidos de macrófagos/células epitelioides/células gigantes multinucleadas e os linfócitos $\mathrm{B}$ foram raramente detectados nos locais de inflamação granulomatosa. O número reduzido de células marcadas por Ki-67 nas lesões granulomatosas, tende a indicar que a proliferação celular não foi responsável pela hipercelularidade das lesões e que o recrutamento de macrófagos e linfócitos para o local da inflamação provavelmente tenha sido o responsável pelo acúmulo de células no infiltrado inflamatório.

TERMOS DE INDEXAÇÃO: Plantas tóxicas, Vicia villosa, Leg. Papilionoideae, intoxicação por planta, doença granulomatosa sistêmica, bovinos, imuno-histoquímica.

\section{INTRODUÇÃO}

Vicia spp. são plantas leguminosas, trepadeiras anuais ou perenes que são amplamente utilizadas como forragem para bovinos devido ao seu alto valor nutricional (Odriozola et al. 1991). O consumo de Vicia villosa Roth (ervilhaca-peluda) pode ocasionar uma doença granulomatosa sistêmica descrita em bovinos e equinos (Panciera et al. 1966, Anderson \& Divers 1983, Panciera et al. 1992, Woods et al. 1992). Em bovinos, a intoxicação tem sido associada a três manifestações clínicas. A primeira é associada ao consumo de sementes causando distúrbios nervosos agudos e a morte dos animais (Claughton \& Claughton 1954). A segunda síndrome está associada ao consumo da pastagem ocasionando pápulas na cabeça, pescoço e corpo, erupções herpetiformes na mucosa oral, descarga nasal purulenta, tosse, avermelhamento das mucosas nasais, queda de pelo, anorexia e respiração ofegante (Panciera et al. 1992). A terceira síndrome é a mais estudada e caracteriza-se por uma doença granulomatosa sistêmica. Clinicamente, esta síndrome é caracterizada por dermatite, prurido, febre, conjuntivite, diarreia, queda da produção de leite e perda de peso (Peet \& Gardner 1986, Barros et al. 2001, Fighera \& Barros 2004). A doença tem sido descrita em bovinos da raça Holandês (Rech et al. 2004), Aberdeen Angus (Peet \& Gardner, 1986, Odriozola et al. 1991, Johnson et al. 1992), Murray Grey, cruzamento de Hereford com Bradford (Harper et al. 1993) e um único caso em uma novilha Limousin (Johnson et al. 1992).

Os bovinos acometidos pela doença granulomatosa sistêmica apresentam lesões de pele caracterizadas por áreas coalescentes de alopecia, formação de pápulas, exsudato amarelado que pode resultar na formação de crostas (Fighera et al. 2005). As lesões de pele estão presentes principalmente na cabeça, pescoço, tronco, períneo e úbere (Fighera et al. 2005). Nódulos branco-acinzentados, moderadamente firmes, multifocais a coalescentes infiltram múltiplos órgãos como linfonodos, fígado, rins e miocárdio. Infiltrado inflamatório constituído de linfócitos, plasmócitos, histiócitos, eosinófilos, macrófagos epitelioides e ocasionalmente células gigantes multinucleadas são observados na histologia (Barros et al. 2001). O infiltrado é mais preva- lente na região do córtex renal, miocárdio, cortical e medular da adrenal, e derme. Órgãos menos frequentemente afetados incluem a tireoide, a parótida, o pâncreas, o baço, os linfonodos e as áreas portais do fígado. Ocasionalmente os infiltrados podem ser observados na traqueia, no pulmão, na vesícula biliar, no intestino, no ovário e no endométrio (Panciera et al. 1992). O tipo de reação inflamatória sugere uma reação de hipersensibilidade tipo IV (Panciera et al. 1992). Este trabalho descreve os achados patológicos observados em bovinos afetados pela doença granulomatosa sistêmica associada com o consumo de Vicia villosa no Rio Grande do Sul.

\section{MATERIAL E MÉTODOS}

Para o presente estudo, bovinos com os sinais clínicos da doença foram necropsiados pelo Setor de Patologia Veterinária (SPV) da Universidade Federal do Rio Grande do Sul (UFRGS). Dados como raça, idade, sexo, sinais clínicos e lesões macroscópicas observados durante a necropsia foram registrados. Um dos bovinos (Bovino 2) foi necropsiado pelo veterinário responsável pelo caso e o material foi encaminhado para histopatologia. Fragmentos de órgãos foram coletados em solução de formalina $10 \%$, processados por técnicas rotineiras de histologia e corados pela hematoxilina e eosina (HE) e Ziehl-Neelsen. Para o teste imuno-histoquímico os cortes de tecidos foram preparados em lâminas com solução de Poli-L-lisina ${ }^{4} 10 \%$ e fixados em estufa a $60^{\circ} \mathrm{C}$ por 24 horas. Utilizou-se o método estreptavidina ligada à peroxidase para os anticorpos anti-CD68 (macrófago), anti-Ki-67 (marcador de proliferação celular) e antiCD79 $\alpha$ (linfócitos B). Inicialmente, a peroxidase endógena foi inibida com peróxido de hidrogênio $3 \%$ por 15 minutos. Para a recuperação antigênica utilizou-se proteinase $\mathrm{K}^{5}$ por 10 minutos (CD68), calor em panela de pressão a $125^{\circ} \mathrm{C}$ por 7 minutos em tampão citrato $\mathrm{pH}$ 6,0 (Ki-67) e calor em microondas por 2 vezes de 5 minutos em tampão citrato $\mathrm{pH}$ 6,0 (CD79 $\alpha$ ). Os anticorpos monoclonais anti-CD68 ${ }^{6}$, anti-Ki-677 e anti-CD79 $\alpha^{8}$ foram diluídos em 1:100, 1:300 e 1:10 respectivamente. As lâminas foram incubadas em câmara úmida overnight a $4^{\circ} \mathrm{C}$ e com revelação com $D A^{5}$. Realizou-se a imuno-histoquímica através da técnica de estreptavidina-biotina ligada à fosfatase alcalina para o marcador de linfócitos T (CD3). Para a recuperação antigênica, neste caso, utilizou-se Protease $\mathrm{XIV}^{4}$ por 15 minutos, diluição de 1:200 do anticorpo policlonal anti-CD3 ${ }^{9} \mathrm{com}$ incubação overnight a $4^{\circ} \mathrm{C}$ e como cromógeno utilizou-se o Permament Red ${ }^{5}$ por 15 minutos.

\section{RESULTADOS}

\section{Dados gerais}

No período de 2005-2008 foram realizadas, no SPVUFRGS, 278 necropsias de bovinos, 38 das quais foram associadas a intoxicações por plantas. Realizou-se, nesse período, o diagnóstico de 5 surtos de intoxicação por

\footnotetext{
${ }^{4}$ Sigma Chemical Company, Poole, UK.

5 Dako, Carpintaria, CA, USA..

${ }^{6}$ Dako M0718, DakoCytomation, Carpintaria, CA, USA.

7 Dako F0788, DakoCytomation, Carpintaria, CA, USA.

8 Dako M7050, DakoCytomation, Carpintaria, CA, USA.

9 Dako A0452, DakoCytomation, Carpintaria, CA, USA.
} 
Quadro 1. Dados dos bovinos e das propriedades de cinco municípios do Rio Grande do Sul onde ocorreram casos de doença granulomatosa sistêmica pelo consumo de Vicia villosa

\begin{tabular}{|c|c|c|c|c|c|c|c|c|}
\hline Bovino & Raça & Sexo & $\begin{array}{l}\text { Idade } \\
\text { (anos) }\end{array}$ & $\begin{array}{l}\text { Duração dos } \\
\text { sinais clínicos }\end{array}$ & Município & $\begin{array}{l}\text { Total de bovinos } \\
\text { na propriedade }\end{array}$ & $\begin{array}{l}\text { Época de } \\
\text { ocorrência }\end{array}$ & $\begin{array}{c}\text { Morbidade } \\
(\%)\end{array}$ \\
\hline 1 & Holandês & $\mathrm{F}$ & 5 & 15 dias & Vacaria & 90 & Setembro/2005 & 5,5 \\
\hline 2 & Holandês & $\mathrm{F}$ & 5 & 15 dias & Santo Cristo & 35 & Dezembro/2006 & 8,6 \\
\hline 4 & Holandês & $\mathrm{F}$ & 7 & 15 dias & Tuparendi & 13 & Setembro/2008 & 7,6 \\
\hline 5 & Holandês & $\mathrm{F}$ & 6 & 10-12 dias & Cândido Godoy & 14 & Outubro/2008 & 7,1 \\
\hline
\end{tabular}

Vicia villosa. Os dados dos bovinos e das propriedades estão descritos no Quadro 1.

Na propriedade do Bovino 1, havia um total de 90 bovinos em lactação. Os animais estavam consumindo ração comercial, silagem de milho e pastagem cultivada com aveia, azevém e $V$. villosa. Este havia sido o primeiro ano no qual a ervilhaca era introduzida na alimentação dos bovinos. Após 30 dias da ingestão da planta os bovinos começaram a apresentar queda da produção leiteira, febre, anorexia, prurido intenso e lesões de pele localizadas principalmente na cabeça, pescoço, úbere, abdômen e membros posteriores. Os bovinos foram tratados para dermatomicose sem apresentarem melhora no quadro clínico. No decorrer de duas semanas após o início dos sinais clínicos 4 bovinos morreram e em um foi realizada a eutanásia para a realização da necropsia.

Na propriedade do Bovino 2 havia um total de 35 bovinos; desses, três apresentaram sinais clínicos como diminuição da produção leiteira, febre, anorexia e morte. Os três bovinos morreram, sendo que em um foi realizada a necropsia. Os bovinos dessa propriedade eram mantidos em pastagem contendo $V$. villosa.

Bovino 3 apresentou emagrecimento, diminuição da produção leiteira, diarreia e áreas avermelhadas e alopécicas na pele da face e do úbere com curso clínico de 26 dias. Na mesma propriedade outros dois bovinos haviam apresentado sinais clínicos semelhantes, sendo ambos filhos do Bovino 3. Os bovinos da propriedade eram mantidos em pastagem com aveia, azevém e $V$. villosa.

Bovino 4 era proveniente de uma propriedade com 13 bovinos e foi o único a apresentar sinais clínicos de anorexia, emagrecimento, alopecia e crostas na pele da face e úbere. Os sinais clínicos iniciaram-se 2 meses após o consumo da pastagem contendo $V$. sativa e V. Villosa; o curso clínico foi de 15 dias e após esse período realizou-se a eutanásia do bovino.

Bovino 5 era proveniente de uma propriedade com um total de 14 bovinos que consumiam pastagem contendo aveia, azevém e $V$. villosa por aproximadamente 4 meses. Bovino 5 apresentou anorexia, emagrecimento, queda da produção leiteira e lesões alopécicas e crostosas na face, orelhas e pescoço. O curso clínico da doença foi de 10-12 dias e resultou na morte do bovino.

\section{Achados macroscópicos}

Os achados macroscópicos dos bovinos desse estudo foram principalmente caracterizados por lesões de pele (Bovinos 1, 3, 4 e 5). As lesões observadas foram alopecia e

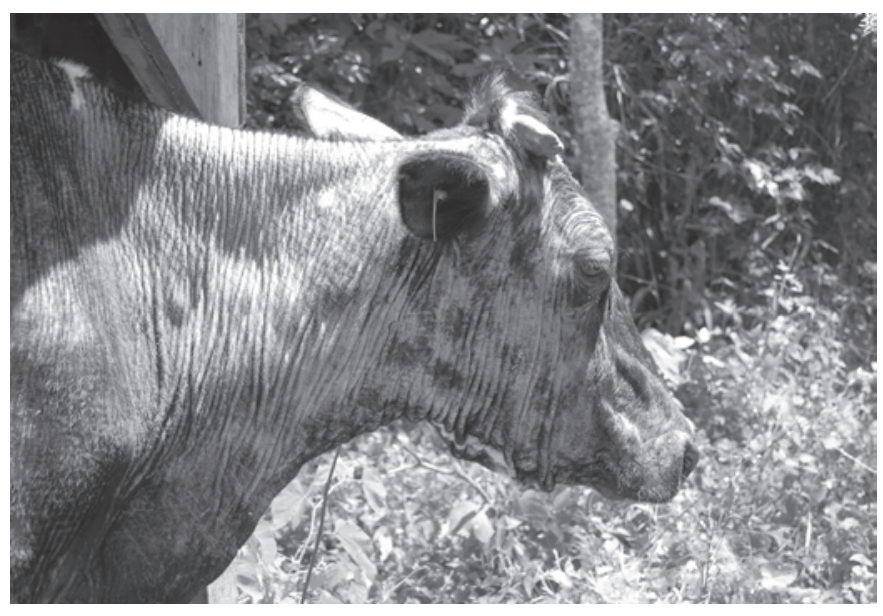

Fig.1. Bovino 3 intoxicado por Vicia villosa com lesões alopécicas e crostosas na face e pescoço.

crostas localizadas principalmente na face, no pescoço (Fig.1), nas orelhas e no úbere. Nódulos esbranquiçados multifocais ou coalescentes infiltravam diferentes órgãos. Os rins encontravam-se aumentados de volume e com numerosos nódulos de 0,1-0,2cm (Bovinos 1, 2, 3 e 5). Áreas esbranquiçadas no miocárdio e hidropericárdio foram observados no Bovino 3, enquanto que numerosos nódulos de $0,2-0,8 \mathrm{~cm}$ foram visualizados no epicárdio e miocárdio do Bovino 1. No Bovino 5, observou-se esplenomegalia com hiperplasia da polpa branca. No fígado, visualizaram-se áreas esbranquiçadas no parênquima hepático do Bovino 3, e hepatomegalia e acentuação do padrão lobular foram evidenciados no Bovino 1. Aumento de volume e múltiplos nódulos esbranquiçados evidenciados ao corte e que variavam de 0,2 0,8cm (Bovinos 1, 2, 4 e 5) foram observados (Fig.2). Os principais linfonodos afetados foram os mamários, mesentéricos, mediastínicos, hepáticos e ilíaco interno. Os linfonodos hepáticos se apresentavam hemorrágicos e a vesícula biliar apresentava-se com petéquias no Bovino 2. Evidenciação das placas de Peyer foi observado no Bovino 1. No Bovino 4, a principal alteração macroscópica observada foi o aumento acentuado das adrenais principalmente da adrenal direita. No Bovino 5 observaram-se hemorragias no tecido subcutâneo, rins, bexiga, coração e intestino.

\section{Achados microscópicos}

Os achados histológicos observados foram infiltrado inflamatório constituído de linfócitos, histiócitos, células epitelioides, células gigantes multinucleadas, plasmócitos 


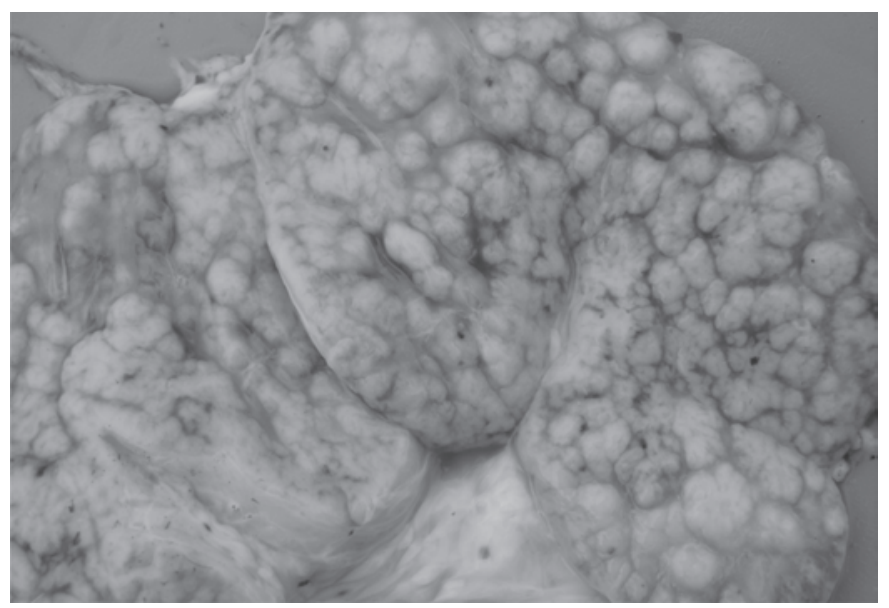

Fig.2. Superfície de corte de linfonodo do Bovino 5 afetado por doença granulomatosa sistêmica associada à ingestão de Vicia villosa. Observam-se nódulos brancacentos e salientes.

e eosinófilos. O infiltrado de eosinófilos foi raramente observado nos Bovinos 2 e 5 . O infiltrado granulomatoso foi observado em múltiplos órgãos (Fig.3), como descrito no Quadro 2. Nenhum microorganismo foi observado através das colorações de hematoxilina-eosina (HE) e ZiehlNeelsen nos cortes analisados. Na pele dos bovinos analisados foram observados além do infiltrado inflamatório granulomatoso, que se localizava principalmente perivascular, crostas na epiderme, acantose discreta e dilatação de glândulas sudoríparas, que foram visualizados nos em todos os bovinos no qual a pele foi coletada (Bovino 1, 3, 4 e 5). Em um dos bovinos (Bovino 1) visualizou-se foliculite multifocal moderada. Os órgãos que apresentavam infiltrado granulomatoso, foram principalmente adrenal, baço, fígado, linfonodos e rins.

\section{Resultados imuno-histoquímicos}

Nos órgãos que apresentavam infiltrado granulomatoso, realizaram-se testes imuno-histoquímicos através de

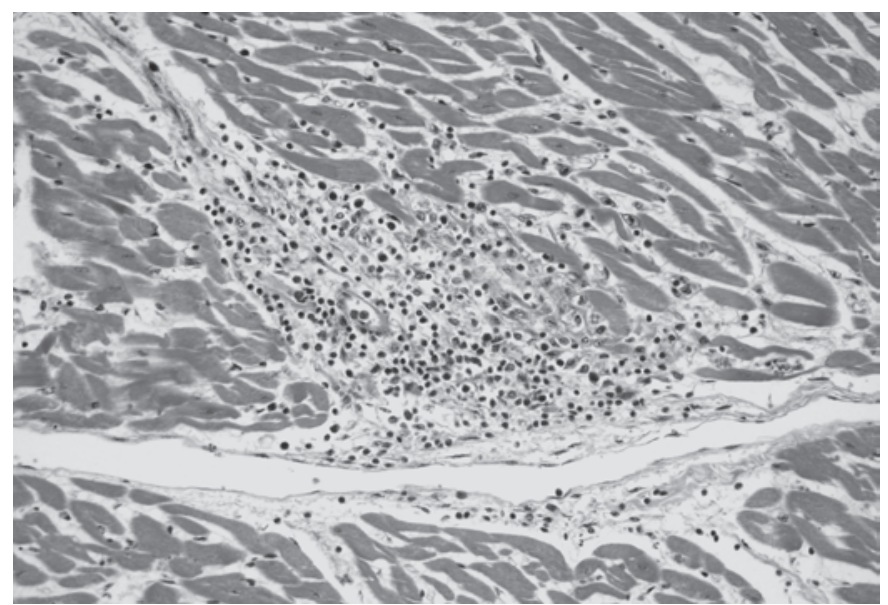

Fig.3. Miocárdio do Bovino 5 afetado por doença granulomatosa sistêmica associada à ingestão de Vicia villosa. Observa-se foco inflamatório focalmente extenso constituído por linfócitos e macrófagos. HE, obj.20x.
Quadro 2 . Distribuição e intensidade do infiltrado granulomatoso no exame microscópico de diferentes órgãos de bovinos com doença granulomatosa sistêmica pelo consumo de Vicia villosa no Rio Grande do Sul

\begin{tabular}{lccccc}
\hline Órgãos & Bovino & Bovino & Bovino & Bovino & Bovino \\
& 1 & 2 & 3 & 4 & 5 \\
\hline Abomaso & - & $\mathrm{NC}$ & - & - & - \\
Adrenal & +++ b & +++ & +++ & +++ & + \\
Baço & +++ & ++ & ++ & ++ & + \\
Bexiga & $\mathrm{NC}$ & $\mathrm{NC}$ & $\mathrm{NC}$ & $\mathrm{NC}$ & - \\
Cerebelo & - & - & - & - & - \\
Cérebro & - & - & - & - & + \\
Coração & +++ & $\mathrm{NC}$ & - & ++ & + \\
Fígado & ++ & +++ & + & + & + \\
Gânglio trigêmeo & - & $\mathrm{NC}$ & - & - & - \\
Intestino & +++ & $\mathrm{NC}$ & - & - & + \\
Linfonodos & +++ & ++ & ++ & ++ & +++ \\
Mama & $\mathrm{NC}$ & $\mathrm{NC}$ & $\mathrm{NC}$ & - & - \\
Medula espinhal & - & $\mathrm{NC}$ & - & - & - \\
Medula óssea & ++ & $\mathrm{NC}$ & $\mathrm{NC}$ & - & ++ \\
Omaso & - & $\mathrm{NC}$ & $\mathrm{NC}$ & - & + \\
Parótida & $\mathrm{NC}$ & $\mathrm{NC}$ & $\mathrm{NC}$ & - & + \\
Pele & ++ & $\mathrm{NC}$ & + & ++ & +++ \\
Pulmão & - & $\mathrm{NC}$ & - & - & ++ \\
Retículo & - & $\mathrm{NC}$ & $\mathrm{NC}$ & - & - \\
Rim & ++ & +++ & +++ & + & +++ \\
Rúmen & - & $\mathrm{NC}$ & - & - & - \\
\hline
\end{tabular}

a NC não coletado; ${ }^{\mathrm{b}}+++$ infiltrado granulomatoso acentuado, ++ moderado, + leve, - ausente.

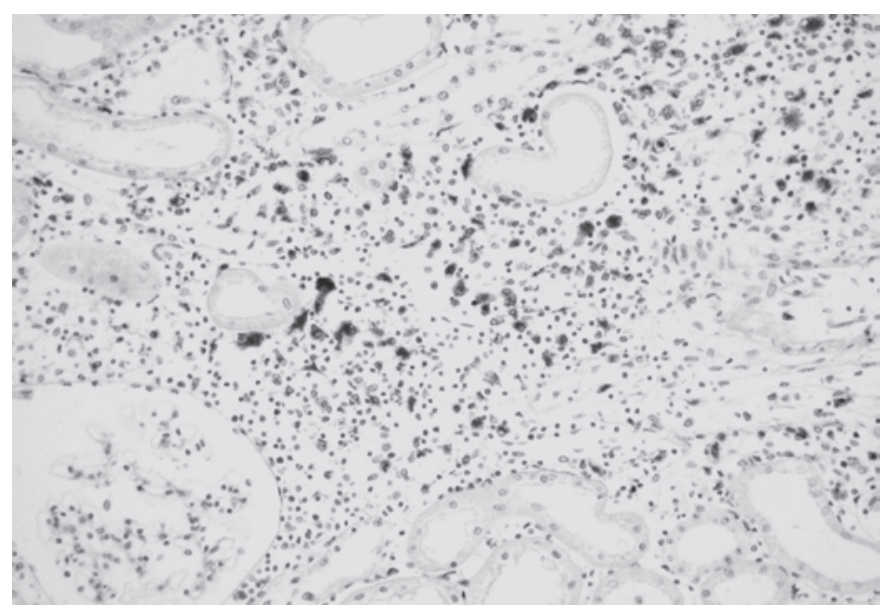

Fig.4. Imuno-histoquímica no rim do Bovino 5 afetado por doença granulomatosa sistêmica, com marcação positiva em macrófagos. Anticorpo anti-CD68, estreptavidina biotina ligada a peroxidase, obj.20x.

cortes seriados com marcadores de linfócitos T (CD3), linfócitos B (CD79á) e macrófagos (CD68). O maior número de células marcadas positivamente foi de macrófagos (Fig.4) e linfócitos T (Fig.5), sendo o último a principal célula presente no infiltrado. Na pele a marcação positiva ocorreu na derme superficial principalmente ao redor de vasos. Em órgãos como linfonodos e baço, no qual há normalmente um acentuado número de linfócitos, esses foram melhor evidenciados principalmente com o marcador de linfócitos $T$, representando um acentuado aumento dessas células nesses órgãos. Macrófagos, 


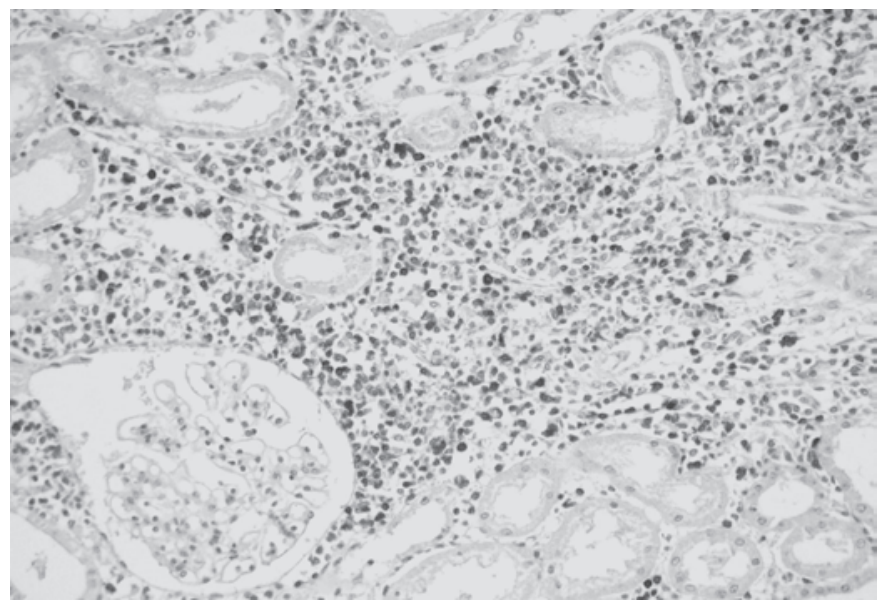

Fig.5. Imuno-histoquímica no rim do Bovino 5 afetado por doença granulomatosa sistêmica, com linfócitos T marcados positivamente. Anticorpo anti-CD3, estreptavidina biotina ligada a fosfatase, obj.20x.

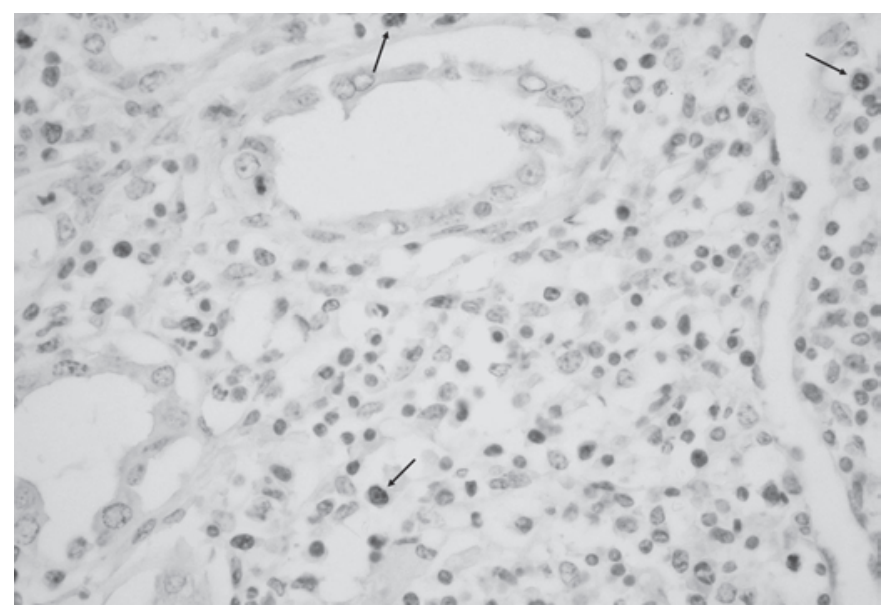

Fig.6. Imuno-histoquímica no rim do Bovino 5 afetado por doença granulomatosa sistêmica, com células marcadas positivamente para Ki-67 (setas). Anticorpo anti-Ki-67, estreptavidina biotina ligada a peroxidase, obj.20x.

células epitelioides e células gigantes multinucleadas foram marcados intensamente com o anticorpo anti-CD68. Inúmeros macrófagos foram observados principalmente nos cortes de baço dos Bovinos 1 e 3 . Os linfócitos $B$ e plasmócitos foram identificados pelo anticorpo anti-CD79 $\alpha$, porém com um menor número de células marcadas positivamente no cortes avaliados. Quando se utilizou o anticorpo anti-Ki-67 (Fig. 6) obteve-se um pequeno número de marcação positiva nuclear em células do infiltrado inflamatório.

\section{DISCUSSÃO E CONCLUSÕES}

A intoxicação natural por Vicia villosa foi diagnosticada em cinco bovinos de diferentes propriedades no período de 2005 a 2008. Os aspectos epidemiológicos, clínicos e patológicos encontrados foram semelhantes aos previamente descritos (Panciera et al. 1966, Barros et al. 2001). As taxas de morbidade nas propriedades variaram de 5,5\% a $20 \%$ e a letalidade foi de $33 \%$ (Rodeio Bonito, Bov.3) e $100 \%$ nas demais propriedades. Fighera \& Barros (2004) relataram surtos da doença granulomatosa sistêmica com morbidade variando entre $2,8 \%$ a $33,3 \%$ e letalidade de $100 \%$ em 8 pequenas propriedades do Rio Grande do Sul.

Os bovinos intoxicados naturalmente apresentavam lesões bastante características como alopecia e formação de crostas na pele, principalmente na cabeça, pescoço e mama, como também foram descritas por outros autores (Panciera et al. 1966, Fighera et al. 2005). Múltiplos órgãos foram afetados, e a principal alteração macroscópica encontrada foram nódulos esbranquiçados nos órgãos como rins, linfonodos e coração. O aumento de volume da adrenal foi um achado importante; na histologia dessa glândula observou-se infiltrado granulomatoso em todos os bovinos examinados e essa foi a principal alteração macroscópica no Bovino 4.

As alterações de pele foram analisadas em quatro bovinos, em um deles (Bovino 2) o órgão não foi enviado para a análise histológica. Alterações como crostas na epiderme, dilatação de glândulas sudoríparas e infiltrado inflamatório de linfócitos, histiócitos, células epitelioides, eosinófilos e com raras células gigantes multinucleadas foram encontrado nos quatro bovinos analisados. As lesões se caracterizavam por dermatite perivascular superficial. Linfonodos, rins, baço e fígado foram órgãos que apresentaram na histologia infiltrado inflamatório granulomatoso nos cinco bovinos estudados.

Os testes imuno-histoquímicos dos bovinos estudados demonstraram que o infiltrado inflamatório era constituído principalmente por macrófagos, células epitelioides, células gigantes multinucleadas e linfócitos. Quando comparados os mesmos cortes, a imunofenotipagem linfocitária revelou que, em todos os locais avaliados, os linfócitos $T$ predominavam, enquanto os do tipo $B$ raramente eram encontrados. Esses achados reforçam o envolvimento da reação de hipersensibilidade tardia na patogênese da doença. O número reduzido de células marcadas por Ki-67 indica que a proliferação celular não foi o principal responsável pela hipercelularidade observada nas lesões granulomatosas por consumo de $V$. villosa, e que o recrutamento de macrófagos e linfócitos para o local da inflamação deve ter sido o responsável pelo acúmulo inflamatório (Valheim et al. 2004).

Agradecimentos.- Ao CNPq pelo apoio financeiro e ao professor Claudio Estevão Farias da Cruz pela ajuda na revisão deste artigo.

\section{REFERÊNCIAS}

Anderson C.A. \& Divers T.J. 1983. Systemic granulomatous inflammation in a horse grazing hairy vetch. J. Am. Vet. Med. Assoc. 183:569- 570.

Barros C.S.L., Fighera R.A., Rozza D.B., Rech R.R., Sallis S.V. \& Langohr I.M. 2001. Doença granulomatosa sistêmica em bovinos no Rio Grande do Sul associada ao pastoreio de ervilhaca (Vicia spp). Pesq. Vet. Bras. 21:162-171.

Claughton W. P. \& Claughton H.D. 1954. Vetch seed poisoning. Auburn Vet. 10:125-126.

Fighera R.A. \& Barros C.S.L. 2004. Systemic granulomatous disease 
in brazilian cattle grazing pasture containing vetch (Vicia spp.). Vet. Human Toxicol. 46(2):62-66.

Fighera R.A., Souza T.M. \& Barros C.S.L. 2005. Lesões de pele em bovinos com doença granulomatosa sistêmica associada ao pastoreio de ervilhaca (Vicia spp.). Ciência Rural 35:406-411.

Johnson B., Moore J., Woods L.W. \& Galey F.D. 1992. Systemic granulomatous disease in cattle in California associated with grazing hairy vetch (Vicia villosa). J. Vet. Diagn. Invest. 4:360-362.

Harper P., Coock R.W., Gill P.A., Fraser G.C., Badcoe L.M. \& Power J.M. 1993. Vetch toxicosis in cattle grazing Vicia villosa spp dasycarpa and $V$. benghalensis. Aust. Vet. J. 70:140-144.

Odriozola E., Paloma E., Lopez T. \& Campero C. 1991. An outbreak of Vicia villosa (hairy vetch) poisoning in grazing Aberdeen Angus Bulls in Argentina. Vet. Hum. Toxicol. 33(3):278-280.

Panciera R.J., Johnson L. \& Osburn B.I. 1966. A disease of cattle grazing hairy vetch pasture. J. Am. Vet. Med. Assoc. 148(7):804-808.
Panciera R.J., Mosier D.A. \& Ritchey J.W. 1992. Hairy vetch (Vicia villosa Roth) poisoning in cattle: Update and experimental induction of disease. J. Vet. Diagn. Invest. 4:318-325.

Peet R.L. \& Garden J.J. 1986. Poisoning of cattle by hairy or woollypod vetch, Vicia villosa subspecies dasycarpa. Aust. Vet. J. 63(11):381-382.

Rech R.R., Fighera R.A., Oliveira F.N. \& Barros C.S.L. 2004. Meningoencefalite granulomatosa em bovinos em pastoreio de ervilhaca ( $\mathrm{Vi}$ cia spp). Pesq. Vet. Bras. 24:169-172.

Valheim M., Sigurdardóttir O.G., Storset A.K., Aune L.G. \& Press C.M. 2004. Characterization of macrophages and occurrence of $T$ cells in intestinal lesions of subclinical paratuberculosis in goats. J. Comp. Pathol. 131:221-232.

Woods L.W., Johnson B., Hietala S.K., Galey F.D. \& Gillen D. 1992. Systemic granulomatous disease in a horse grazing pasture containing vetch (Vicia sp.). J. Vet. Diagn. Invest. 4:356-360. 